\title{
PEOPLE-ORIENTED PRINCIPLES AND VALUES OF AGILE PROJECT MANAGEMENT
}

\author{
Marija Todorović, Danijela Toljaga-Nikolić, Dragan Bjelica \\ Faculty of Organizational Sciences, University of Belgrade, Serbia
}

\begin{abstract}
This paper presents the people-oriented elements of agile approach with the focus on Scrum methodology as one of the most applicable of agile methodologies. Comparing to traditional methodology it can be concluded that the agile approach enables learning, project team development encouraging self-organization, better communication and competence development. The focus on the people aspects of the project is essential for achieving effective project results and a positive long-term impact of the project. This paper also emphasizes the role of a project team in the transition process from traditional to agile project management. People capacity to adapt agile approach are influenced by trust, capacity for self-organization, capacity for learning and adoption the value of agile management. From a practical point of view, managers who are people-oriented can accept agile project management as a framework and way of thinking to achieve their goals.
\end{abstract}

Key words: Agile project management, scrum, social aspect.

\section{LEADING TRENDS IN PROJECT MANAGEMENT}

The diffusion of project management into all segments of society is one of the global trends and trends (Kirkman, 2017; Schoper, Gemünden, \& Nguyen, 2015) new tendencies in the field of project management arise under the pressure of numerous technological, economic and social changes, among others: transnationalization, virtualization, social responsibility and sustainability, emotional intelligence and blended methodology.

Many research and professional articles are focused on project's long-term impacts and benefits for different stakeholders but also on impact that different technologies have on project management: artificial intelligence, virtual reality, big data, digitization and social networks. Technological evolution has become an unstoppable mindset. Organizations are now developing their abilities to use new technologies and incorporating them into their business to increase profitability. Artificial intelligence can support the analysis of large quantities of data for business analysis, as a project background, scenario planning, and simulation of real situations, risk analysis, but also for reporting and lessons learned. Platform for virtual reality can be beneficial in dealing with emergence which is crucial for complex projects, while in virtual reality project teams can gain new skills and experience in change management and emergence situation and problem-solving. It can also help project team to learn how to deal with emotions, behavioral patterns, attitude issues (Reuters, 2017).

Digitalization that is present at all levels of society affects project's interactions with stakeholders and within the team. Bearing in mind those technological changes, but also limited resources, temporary engagement of team members, many stakeholders, changing requirements, it can be concluded that the consequence of these changes is the transition from traditional to agile management (Beck, Beedle, Van Bennekum, Cockburn, Cunningham, Fowler, \& Thomas, 2016; Conforto, Salum, Amaral, da Silva, \& de Almeida, 2014). In line with these trends, it is an indispensable question of how to develop a society, without limiting the opportunities for future generations? Profit has always been the main driver in the business world, still the core values in the business are ethics, social and managerial responsibility. Projects are no exception. Their impacts must be monitored because they have a responsibility often 
towards many stakeholders: customers, citizens, state, environment. They all are interested in project sustainability, therefore there is a necessity to create sustainable project management. In this context, sustainable project management refers to ecological, economic and social aspects. The focus on these elements is present and refers to all subprocesses in the project management process, the resources that the project uses and the life cycle of the project's products, after the project completion. Projects can create changes in the system, behaviour, assets, while project products throughout their lifecycle can have different impacts on society and nature (Agarwal \& Kalmar, 2015; GPM, 2015).

\section{NEW PROJECT MANAGEMENT APPROACHES}

\subsection{Transition from traditional to agile project management}

Project management methodology originated from traditional engineering disciplines (Wysocki \& McGary, 2003). The greatest impact on the further growth of project management methodology came from the project's characteristics and complexity within various industries. At the end of the 20th century, a strong impact of IT industry on all social and business segments affected this methodology. In early days of project management in IT industry, the approach that was inherited from other engineering disciplines was used for all projects.

The rapid growth of IT industry often resulted in unsuccessful projects, due to unfulfilled deadlines and due to different expectations of clients. This led to the conclusion that the traditional formal management approach is not suitable for such projects. In parallel with the use of traditional formal management approaches, new dynamic approaches have been developed that allow flexibility and consider all important constraints in terms of time, costs, people, speed of development and unplanned sudden changes within the project plan (Thomsett, 2001).

Through the popularization of the agile method, during the 90 s of the 20th century numerous approaches have been created: Extreme programming, Scrum, Cristal,
Feature-driven development, Adaptive Software Development, Dynamic systems development method, Test-driven development, Lean Development, Agile Unified Process.

\subsection{Scrum approach}

One of the most applicable agile approach is Scrum. Scrum can be defined as an agile framework that allows us to produce the highest business value in the shortest possible time (Goldstein, 2013).

Scrum is aslo defined as a refreshing and simple framework that places people in the center of the sphere, based on the principles of sincerity, openness, courage, respect, focus, trust, empowerment and cooperation (Rubin, 2012).

The next four values contribute to peoplecentered approach:

- Individualism and interaction instead of processes and tools;

- Functional software instead of extensive documentation;

- Cooperation with the client instead of negotiating the contract;

- Reaction to changes instead of monitoring the plan.

The application of the Scrum methodology in other areas is not a rarity. Scrum as an approach to project management used to improve quality in IBM, the Scandinavian company Trifork used this method to improve customer satisfaction, some fashion companies have successfully used Scrum as a way to guide the development of their products and processes. One of the more interesting applications of the Scrum methodology outside the field of information technology development is in the field of education and learning.

The Dutch University Ashram College uses Scrum named eduScrum. They incorporated Scrum as a way of learning to make their students more efficient. Using eduScrum, they succeeded in developing more efficient work in the team. Students are divided into groups of four. The application of Scrum is identical with the fact that in this case the product is knowledge. 


\section{PEOPLE-ORIENTED ASPECT OF AGILE APPROACH WITH FOCUS ON SCRUM METHODOLOGY}

\subsection{People aspect in agile project management}

According to many studies, people aspects are crucial to the implementation of agile approaches in project management, therefore this paper attempts to answer the following research questions:

- Do the principles and methods of agile project management support social aspects?

- How to include team members in the process of transformation from traditional to agile approach?

- How to achieve commitment to this process at all levels?

With frequently implementation of agile methodologies in practice, project managers understand the benefits and become more and more loyal to them in project realization for which they are responsible. On this road they face numerous challenges, but also with the results of the project at a significantly higher level. According to Ambler (2010) the implementation of the agile methodology productivity increased in $82 \%$ of cases, the quality was improved to $77 \%$, the client's satisfaction was increed to a higher level in $78 \%$, while the development costs decreased to $72 \%$ of cases. In order to analyze the presence of people aspects in an agile approach we were focused first on basic principles of the agile approach (Conforto et al., 2014):

- Customer satisfaction through continuous delivery of value

- Joint work of all project partners

- Support for changes even in late stages of the project

- Frequently delivering work versions

- Positive working atmosphere and work with motivated team members,

- Working versions are a real measure of progress on the project

- Promotion of face-to-face communication

- Focus on technical excellence

- Sustainable pace of work

- Simplicity - the art of focusing on the most effective way of creating value
- Self-organized teams create the highest value

- Adapting the behavior of team members as a reflection of the previous phase.

Among those principles of agile project management, which can be applied to projects in different industries and segments of society, those that are related to the people aspects are: support for change even in later phases of the project, joint work of all partners on the project, positive working atmosphere and work with motivated team members, face-to-face communication, sustainable pace of work (Cho, 2008; Cobb, 2011; Measey, 2015). In addition to the aforementioned, the social aspect can be seen through a principle that emphasizes the effect of self-organized teams and the principle of adapting the behavior of team members as a reflection of the previous phase (as it adapts project work and revises results).

These principles support the basic elements of sustainable project management from the people aspect, such as: diversity, selforganization, learning capacity, trust, joint access, with a strong positive impact on motivation, better communication and collaboration, reduction of stress and learning, which consequently influences the development of competences (Albarosa \& Valenzuela Musura, 2016). According to Whiwort and Biddle (2007) agile methodology supports a holistic team involvement, awareness, mutual dependency on the team and collective effort.

\subsection{People aspect of Scrum methodology}

In addition to analyzed principles of agile project management in general, we were focused on Scrum methodology. The planning process in Scrum requires only necessary work to be planned. However, scrum teams often spend more time planning than traditional teams, they are more focused on uncertainty of the project and changes in the environment. The basic principles of the scrum planning are listed below:

- Participants realize that they do not need to have a detailed project plan at the beginning because they do not have enough information and can not anticipate everything in advance. 
- Advance planning should be done to a certain extent, as much as the given situation allows, which generally involves the first two or three sprints, but depends on the circumstances.

- If team is not sure that something will happend they should not plan until the last moment. It is also preferable to keep the options open as it is possible, while this reduces the possibility of errors.

- The focus on more on adaptation and revision of plans rather than the desire to achieve the original plan

- Adequately manage the inventory, which means maintaining a balance between planning ahead and planning just-in-time, which will eliminate unnecessary costs on the project.

- Focus on smaller and more frequent interactions on the project, since they enable faster and more frequent feedback, greater customer/manager satisfaction with faster returns of money invested at the end of each iteration.

- Learn quickly and adapt to changes even faster.

One of the researces showed that agile teams are actually planning more precisely than teams using the sequential process (Cohn, 2009). Another important fact that can be observed is that scrum methodology implies the declaration of project vision, processes, inputs, outputs and decision-making strategies are defined. This is especially important because of the the clarity of a job for individuals, as an important motivation factor (Green, Rosemann, Indulska, \& Recker, 2011; Peterson, 2007).

Scrum uses different strategies to decide what project to implement, how to implement (inflow process-strategy) it and when to withdraw or to "extract" the product from the portfolio. In these strategies, the following rules are defined:

- Focus on ideal work, not ideal workers. An ideal job is the job we want to do, while the concept of an ideal worker refers to its maximum capacity to perform the job.

- Provide a capacity limit.

This refers to the recommendation that we never implement more projects / products than we have the capacity to fulfill.
- Wait to complete team.

The last strategy is to wait for a complete scrum team before the realization starts, otherwise significant delay can occur.

Those strategies help team member to make a decision, to structure their tasks and require constant communication within the project team.

Beside the planning phase, people-centered aspect is recognized when we consider how scrum team works. Scrum methodology uses self-organizing teams with a flat hierarhy. It emphasizes a close collaboration with customers and other supporting teams on a project. This methodology also includs a retrospective meetings after each sprint. Through the presentation of these aspects of Scrum methodology it can be concluded that this methodology empahsize more peoplecentered aspects comparing to traditional project management methodology.

\section{TRANSITION FROM TRADITIONAL TO AGILE PROJECT MANAGEMENT: THE ROLE OF A PROJECT TEAM}

To cope with presented trends in project management project management needs to be more agile, which implicate the need to create ways to evolve and support the transformation process from a traditional to agile management.

In order to adopt an agile approach, it is necessary to analyze (Gandomani, Zulzalil, Ghani, Sultan, \& Nafchi, 2013; Kostić, 2017; Nerur, Mahapatra, \& Mangalaraj, 2005):

- goals (reorientation from a processoriented approach to the orientation to results and people);

- technologies (a new set of skills, techniques and tools);

- management (organizational culture, managerial style, learning system, rewarding system);

- people (competencies and team work).

Boehm and Turner (2005), as the three most important groups of conflicts for moving to the agile approach, point out: conflicts in development processes, business process conflicts and people-related conflicts. The elements for strengthening capacity of people 
to accept the process of transformation towards agile approach are (Gholami \& Heinzl, 2013):

- Trust - most affects the motivation of team members and co-operation;

- Capacity for self-organization - based on the principle of agile project management that self-organized teams achieve the best results;

- Capacity for learning - learning and finding new solutions is considered extremely important for team development and achieving results;

- Adopting the value of agile management - in addition to introducing procedures, a change in the way of thinking is necessary.

Espinosa-Curiel, Rodríguez-Jacobo, VázquezAlfaro, Fernández-Zepeda, \& Fajardo-Delgado (2018) analyzed the behavior of the teams in the process of transformation from a traditional to agile approach - based on the collected data of communication and interactions in the phase when they functioned according to the traditional principle and phase when they worked as an agile team. The conclusion of the research is that this transformation process affects formal, informal, verbal and written communication and increases the number of communication links. Based on the perception of employees in the company that uses agile project management, the authors identified five key challenges of the transformation process, caused by the application of the Scrum methodology: integration and functioning of the agile team; empowering employees, creating an environment that supports learning, balancing formal communication, and managing conflicts.

\section{CONCLUSION}

This paper presents the people-oriented elements of agile approach with the focus on Scrum methodology as one of the most applicable of agile methodologies. Based on analyzed element it can be concluded that the agile approach contributes to increased flexibility and responsiveness to change and enables learning. The basic principles of agile project management significantly contribute to the development of project team members, encouraging self-organization, better communication, learning and competence development. The focus on the people aspects of the project is essential for achieving effective project results and a positive longterm impact of the project. This paper also emphasizes the role of project team to transformation process from traditional to agile project management. People capacity to adapt agile approach are influenced by trust, capacity for self-organization, capacity for learning and adoption the value of agile management. From a practical point of view, managers who want to point out a people-centered approach can accept agile project management as a framework and way of thinking to achieve their goals. Also, organizations that already use agile approach can become more aware of their impact on the dynamics of internal processes and internal connections, highlighting that added value.

\section{Acknowledgments}

This paper is the result of the project of basic research "Exploring modern trends of strategic management of the application of specialized management disciplines in the function of the competitiveness of Serbian economy", no. 179081, funded by Ministry of education, science and technological development of the Republic of Serbia.

\section{REFERENCE}

Albarosa, F., \& Valenzuela Musura, R. (2016). Social sustainability aspect of agile project management, Umeå School of Business and Economics.

Agarwal, R. S. T., \& Kalmar, T. (2015). Sustainability in project management Eight principles in practice, Umeå School of Business and Economics, Sweeden.

Ambler, S. (2010). Scrum Certification Survey Results, Ambysoft, Canada.

Beck, K., Beedle, M., Van Bennekum, A., Cockburn, A., Cunningham, W., Fowler, M., \& Thomas, D. (2016) The Agile Manifesto. Manifesto for Agile Software Development, Retrieved November 15, from http://agilemanifesto.org/

Boehm, B., \& Turner, R. (2005). Boehm, B., Turner, R. (2005). Management challenges to implementing agile processes in traditional development organizations, IEEE software 22.5 pp. 3039. 
Cho, J. (2008). Issues and Challenges of Agile Software Development with SCRUM, Issues in Information Systems, Vol. 9, pp. 188-195.

Cohn, M. (2009). Succeeding with Agile, Addison Wesley, Mike Cohn Signature Book Series.

Cobb, C. G. (2011). Making sense of agile project management: Balancing control and agility, Hoboken, N.J: Wiley.

Conforto, E. C., Salum, F., Amaral, D. C., da Silva, S. L., \& de Almeida, L. F. M. (2014). Can agile project management be adopted by industries other than software development?. Project Management Journal, 45(3), 21-34.

Espinosa-Curiel, I. E., Rodríguez-Jacobo, J., Vázquez-Alfaro, E., Fernández-Zepeda, J. A., \& Fajardo-Delgado, D. (2018). Analysis of the changes in communication and social interactions during the transformation of a traditional team into an agile team. Journal of Software: Evolution and Process, 30(9), e1946.

Gandomani, T. J., Zulzalil, H., Ghani, A. A., Sultan, A. B., \& Nafchi, M. Z. (2013). Obstacles in moving to agile software development process; At a glance. Journal of Computer Science, 9(5), 620-625.

Gholami, B., \& Heinzl, A. (2013). Leading Agile Self-Organizing Teams : A Collective Learning Perspective. Retrieved 12 24, 2018, from https://ubmadoc.bib.uni-mannheim.de/33452

Goldstein, I. (2013). Scrum Shortcuts, Addison-Wesley, Mike Cohn Signature Book Series.

Green Project Management, (2015). The GPM P5 Standard for Sustainability in Project Management, USA, https://greenprojectmanagement.org/

Green, P., Rosemann, M., Indulska, M., \& Recker, J. (2011). Using Agile Practices to Influence Motivation within IT Project Teams. Scandinavian Journal of Information Systems, 23(1), 3.

Kirkman, N. (2017) Four Key Digital Project Management Trends to Consider for 2018,
Inside Big Data. Retrieved from https://insidebigdata.com/2017/08/31/fou r-key-digital-project-management-trendsconsider-2018/

Kostić, M. (2017). Challenges of Agile Practices Implementation in the Medical Device Software Development Methodologies, European Project Management Journal, 7(2), pp. 36-44.

Measey, P. (2015). Agile Foundations: Principles, Practices and Frameworks, (Radstad, Ed.). Swindon, SN2 1FA, UK: BCS Learning \& Development Ltd.

Nerur, S., Mahapatra, R. K., \& Mangalaraj, G. (2005). Challenges of migrating to agile methodologies. Communications of the ACM 48.5, pp. 72-78.

Peterson, T. M. (2007). Motivation: How to Increase Project Team Performance. Project Management Journal, 38(4), 6069.

Reuters, (2017). Global Virtual Reality Market Forecast 2020 by Major Players such as Sony, Microsoft, Facebook, HTC, Google, Samsung Electronics, GoPro, etc, https://www.reuters.com/brandfeatures/v enture-capital/article?id=4975

Rubin, S. K. (2012). Essential Scrum, Kenneth S. Rubin, Addison-Wesley, Mike Cohn Signature Book Series.

Schoper, Y. G., Gemünden, H. G., \& Nguyen, N. M. (2015). "Fifteen future trends for Project Management in 2025, IPMA Expert Seminar. Zurich, International Project Management Association

Thomsett, R. (2001). Extreme Project Management, Executive Report, Cutter Consortium, Vol.2, No. 2.

Wysocki, K. R., \& McGary, R. (2003). Effective Project Management, Third Edition, Indianapolis, IN:John Wiley \& Sons, Inc.

Whiwort, E., \& Biddle, R. (2007). The Social Nature of Agile Teams, Agile Conference (AGILE), IEEE; Washington, DC, USA. 